\title{
Technologists' Forum Roundtable Discussion: Doing Great Science on a Tight Budget.
}

\author{
John P. Chandler ${ }^{1}$ \\ 1. Metallurgical \& Materials Engineering Department, Colorado School of Mines, Golden, USA.
}

Operating a laboratory, whatever its purpose, can be a challenge in many ways. One of the big issues concerns operating within a budget, or at least operating within the limits of available funds. This applies to labs in academia and industry.

This forum will address many of these challenges. A panel of experienced laboratory managers from academia and industry will present their approach to several of the challenges they face to provide the best service to their customers. Their experiences will be applicable to a broad spectrum of situations, and attendees will, hopefully, find solutions to their problems where they might not have previously considered. Following brief presentations from the panel, the floor will be opened to questions and discussions from the audience. Please bring your questions, concerns and solutions to share with your colleagues.

Some of the issues that will be presented will include the following.

The day-to-day processes of keeping adequate supplies to do the job, whatever that may be, requires attention to many factors. Finding the best price for supplies is an ongoing issue. Also, finding a reliable source can be difficult. In microscopy, we are fortunate to have many specialized suppliers who provide excellent service. And, these suppliers listen to what we need. One example is the need for specialized sample holders for our microscopes. Not long ago, there were limited choices. Fabrication of these by individual labs was time consuming and could be expensive. Requests from us, their customers, have resulted in an increasing selection. The message here is to be willing to encourage your favorite vendor to provide the supplies that you need.

Service contracts are often the biggest expense in a lab, second only to salaries. How do you handle that? The money must come from somewhere. Many institutions provide at least part of the cost, but how do you balance the need to charge your customers with making that cost acceptable to them? One way to reduce contract costs is to handle service and repairs in-house. However, that depends on the expertise to which you have access.

The ability to provide excellent service to users and customers of a lab can be a challenge. One, sometimes troublesome, limitation to an analyst is the client's budget for analysis. Labs are oftentimes faced with someone asking for as much information as they can obtain, but they only have a few hundred dollars allotted to the analysis. At this point, there is some education required for both parties, in order to a) determine the actual problem to be solved; and b) explain to the client that the analyst may not be able to provide the ultimate answer for a few hundred dollars, but he or she can many times provide a direction to pursue. An honest discussion can usually help sort these out.

A more frustrating budgetary limitation to great science is the sophistication of the instrumentation available in one's lab. Many new researchers have come from graduate schools where they have had 
access to new and/or higher tech equipment. The researchers want to obtain the same level of information from the (sometimes) multipurpose instrument that is appropriate for a broad usage industrial lab, and are not happy to find out that the analyst may need to outsource the work to a local university or center of excellence. The client typically balks at paying for analyst time AND outside instrument time and then complains about the analyst, the instrument and the sad state of affairs in the lab. Sometimes, the work must be paid for by the analyst's lab, just to prove that the external technique is the better way. This also presents an educational opportunity for the analyst - to educate the clients on why a central analytical facility purchases instruments that serve the broad range of clients rather than specialized ones that may sit unused for weeks or months at a time.

There can be times when reducing the cost of analysis cannot be justified. When there are regulations that require specific procedures be followed, as in a clinical setting, reduction in cost can be difficult, if not impossible. In these situations, support by the institutional administration becomes important. 